\title{
Synthesis of the Polymer with Polar Side Groups. I. The Syntheses and Polymerizations of 2-(2, 2-Dicyanoethylene)-2, 3- dihydropyran, 2-2(-Cyano-2-carboethoxyethylene)-2, 3-dihydropyran and 2-(2, 2-Dicarboalkoxyethylene)-2, 3-dihydropyran
}

\author{
Yasuo Oshiro, Yasuhiko Shirota, and Hiroshi Mikawa \\ Department of Applied Chemistry, Faculty of Engineering, Osaka University, \\ Suita, Osaka, Japan.
}

(Received August 21, 1971)

\begin{abstract}
For the purpose of obtaining a polymer with a high dielectric constant, a new monomer, 2-(2, 2-dicyanoethylene)-2, 3-dihydropyran, was synthesized and polymerized with cationic initiators such as $\mathrm{BF}_{3} \mathrm{OEt}_{2}, \mathrm{I}_{2}$ and $\mathrm{SnCl}_{4}$ in dichloromethane, carbon tetrachloride or in diethyl ether at $25^{\circ} \mathrm{C}$ or at $-78^{\circ} \mathrm{C}$. Also, related monomers, 2-(2-cyano-2-carboethoxyethylene)-2, 3-dihydropyran and 2-(2, 2-dicarboalkoxyethylene)2, 3-dihydropyran were synthesized and polymerized with cationic initiators described above. Polymerization features were compared among these monomers and complex formation of the monomer with the catalyst was indicated in the case of 2-(2, 2-dicyanoethylene)-2, 3-dihydropyran. The infrared spectra of the polymers indicated that the polymer had the tetrahydropyran ring and that the polymerization proceeded at the vinylic double bond. The dielectric constants $(\varepsilon)$ measured at $1 \mathrm{kHz}$ were 5.25 , for poly[2-(2, 2-dicyanoethylene)-2, 3-dihydropyran], 4.38 for poly[2-(2, 2-dicarboethoxyethylene)-2, 3-dihydropyran] and 8.70 for poly[2-(2-cyano-2-carboethoxyethylene)-2, 3-dihydropyran], respectively.
\end{abstract}

KEY WORDS Cationic Polymerization / Polymer with Polar Side Groups / 2-(2, 2-Dicyanoethylene)-2, 3-Dihydropyran / 2-(2-Cyano2-carboethoxyethylene)-2, 3-Dihydropyran / 2-(2, 2-Dicarboalkoxyethylene)-2, 3-Dihydropyran / Complex Formation of Monomer with Catalyst /

In order to obtain a polymer with a high dielectric constant, it is necessary, according to Debye's "dipole theory," that the polymer has a large permanent dipole. The polar polymer may be classified largely into three categories: ${ }^{1}$ (1) a polymer with a permanent dipole parallel to the main chain, (2) a polymer with a permanent dipole perpendicular to the main chain, (3) a polymer with flexible, polar side groups. Concerning the polymer in the first category, it is known that the dielectric relaxation is found at relatively low frequency regions and that the relaxation time is dependent on the degree of polymerization. On the other hand, with regard to the polymer belonging to the second and third categories, it is known that the dielectric relaxation is found at relatively highfrequency regions, the relaxation time being independent of the degree of polymerization.

Our interest in the polymer belonging to the third category led us to the synthesis of a new polymer with dicyanoethylene moiety as flexible, polar side groups, since dicyanoethylene derivatives are known to have a large dipole moment. $^{2}$ This paper deals with the synthesis of 2-(2,2-dicyanoethylene)-2, 3-dihydropyran and its polymerization by cationic initiators such as $\mathrm{BF}_{3} \mathrm{OEt}_{2}, \mathrm{I}_{2}$ and $\mathrm{SnCl}_{4}$. Also, the synthesis and polymerizations of related monomers, 2-(2-cyano2-carboethoxyethylene)-2, 3-dihydropyran and 2(2, 2-dicarboalkoxyethylene) - 2, 3-dihydropyran are described.

In addition, preliminary results of the dielectric properties of the polymers obtained are briefly described. 


\section{EXPERIMENTAL}

\section{Materials}

Acrolein dimer was obtained commercially and purified by distillation, bp $61^{\circ} \mathrm{C}(30 \mathrm{~mm})$. Commercially available malononitrile of $\mathbf{G} . \mathbf{R}$. grade was dried by refluxing over calcium hydride and distilled under reduced pressure in a stream of dry nitrogen, bp $78^{\circ} \mathrm{C}(10 \mathrm{~mm})$. Ethyl cyanoacetate, methyl malonate and ethyl malonate of $\mathbf{G}$. R. grade were distilled under reduced pressure in a stream of dry nitrogen, bp $68^{\circ} \mathrm{C}(1 \mathrm{~mm}), 86^{\circ} \mathrm{C}(18 \mathrm{~mm})$ and $98^{\circ} \mathrm{C}(24$ $\mathrm{mm})$, respectively. $\beta$-Alanine and sodium acetate of G. R. grade were used without further purification. The polymerization solvent, dichloromethane, carbon tetrachloride and diethyl ether were carefully purified and dried as usual and distilled immediately before use. The polymerization catalysts, $\mathrm{SnCl}_{4}$ and $\mathrm{BF}_{3} \mathrm{OEt}_{2}$, were purified by distillation under reduced pressure in a stream of dry nitrogen. $I_{2}$ was purified by sublimation.

\section{Syntheses of Monomers}

2-(2, 2-Dicyanoethylene)-2, 3-dihydropyran. Freshly distilled acrolein dimer $(12.5 \mathrm{~g}, 0.11 \mathrm{~mol})$ and malononitrile $(7.3 \mathrm{~g}, 0.11 \mathrm{~mol})$ were dissolved in $50 \mathrm{~m} l$ EtOH in a three-necked flask equipped with a mechanical stirrer at room temperature. When sodium acetate $(100 \mathrm{mg})$ was added to accelerate the condensation reaction, the temperature of the solution rose slightly and the solution became yellow. After thirty minutes, the solvent was removed in vacuo. The product obtained was dissolved in $100 \mathrm{~m} l$ benzene, washed with five $50 \mathrm{~m} l$ portions of aqueous solution saturated with sodium chloride, dried over anhydrous calcium chloride overnight and then distilled, bp $81.5-83^{\circ} \mathrm{C}(0.3 \mathrm{~mm})$. The yield was $12.8 \mathrm{~g}$ (73\%). The results under various reaction conditions are listed in Table I.

Mass spectrum: $\mathrm{M}^{+}=160$. (Calcd for $\mathrm{C}_{9} \mathrm{H}_{8} \mathrm{~N}_{2} \mathrm{O}$ $=160$.)

Found: C, 67.08; H, 4.94; N, 17.73.

Calcd for $\mathrm{C}_{9} \mathrm{H}_{8} \mathrm{~N}_{2} \mathrm{O}: C, 67.48 ; \mathrm{H}, 5.03 ; \mathrm{N}$, 17.49.

2-(2-Cyano-2-carboethoxyethylene)-2,3-dihydropyran. Freshly dislled ethyl cyanoacetate $(16 \mathrm{~g}$, $0.15 \mathrm{~mol})$ and acrolein dimer $(24 \mathrm{~g}, 0.15 \mathrm{~mol})$ were dissolved in $50 \mathrm{ml} \mathrm{EtOH}$, to which was added $300 \mathrm{mg}$ of sodium acetate. The reaction mixture was refluxed for $2 \mathrm{hr}$ and then the solvent was removed in vacuo. The crude product was washed, dried over anhydrous calcium chloride, and distilled, bp $110^{\circ} \mathrm{C}(0.7 \mathrm{~mm})$. The yield was $15 \mathrm{~g}(47 \%)$.

Mass spectrum: $\mathbf{M}^{+}=207$. (Calcd. for $\mathrm{C}_{11} \mathrm{H}_{13}$ $\mathrm{NO}_{3}=207$.)

Found: C, 63.58; H, 6.39; N, 6.91.

Calcd for $\mathrm{C}_{11} \mathrm{H}_{13} \mathrm{NO}_{3} ; \mathrm{C}, 63.75 ; \mathrm{H}, 6.32 ; \mathrm{N}$, 6.76 .

2-(2, 2-Dicarboethoxyethylene)-2, 3-dihydropyran. A similar procedure described above was followed. Ethyl malonate $(16.5 \mathrm{~g}, 0.1 \mathrm{~mol})$, acrolein dimer $(12.3 \mathrm{~g}, 0.12 \mathrm{~mol})$ and sodium acetate $(500 \mathrm{mg})$ were dissolved in $50 \mathrm{ml} \mathrm{EtOH}$ and refluxed for $4 \mathrm{hr}$. The product, bp $125^{\circ} \mathrm{C}$ $(3 \mathrm{~mm})$, was obtained in a $36 \%$ yield $(9.3 \mathrm{~g})$.

Mass spectrum: $\mathrm{M}^{+}=254$. (Calcd for $\mathrm{C}_{13} \mathrm{H}_{18} \mathrm{O}_{5}$ $=254$.)

Found: C, 61.10; H, 7.20.

Calcd for $\mathrm{C}_{13} \mathrm{H}_{18} \mathrm{O}_{5}: \mathrm{C}, 61.40 ; \mathrm{H}, 7.14$.

2-(2, Dicarbomethoxyethylene)-2, 3-dihydropy-

Table I. Synthesis of 2-(2, 2-dicyanoethylene)-2, 3-dihydropyran

\begin{tabular}{ccccccc}
\hline $\begin{array}{c}\text { Acrolein dimer, } \\
\text { mol }\end{array}$ & $\begin{array}{c}\text { Malononitrile, } \\
\text { mol }\end{array}$ & $\begin{array}{c}\text { Catalyst, } \\
\mathrm{mmol}\end{array}$ & $\begin{array}{c}\text { Solvent EtOH, } \\
\mathrm{m} l\end{array}$ & $\begin{array}{c}\text { Reaction time, } \\
\text { min }\end{array}$ & $\begin{array}{c}\text { Reaction } \\
\text { temp, }{ }^{\circ} \mathrm{C}\end{array}$ & $\begin{array}{c}\text { Yield, } \\
\%\end{array}$ \\
\hline 0.165 & 0.165 & $1.2^{\mathrm{a}}$ & 30 & 60 & 30 & 50 \\
0.24 & 0.24 & $2.4^{\mathrm{a}}$ & 40 & 120 & 30 & 46 \\
0.11 & 0.11 & $1.0^{\mathrm{a}}$ & 50 & 30 & 50 & 73 \\
0.28 & 0.28 & $1.6^{\mathrm{a}}$ & 50 & 30 & 50 & 93 \\
0.14 & 0.14 & $1.0^{\mathrm{b}}$ & 50 & 120 & Reflux & 34 \\
0.11 & 0.11 & $1.25^{\mathrm{b}}$ & 50 & 60 & 30 & 68 \\
0.22 & 0.22 & 8 drops $^{\mathrm{c}}$ & 150 & 60 & 30 & 0 \\
\hline${ }^{\mathrm{a}} \mathrm{CH}_{3} \mathrm{COONa}$ & ${ }^{\mathrm{b}} \beta$-Alanine & ${ }^{\mathrm{c}}$ Piperidine & & & &
\end{tabular}


Synthesis of the Polymer with Polar Side Groups I.

ran. The same procedure with the preparation of 2-(2, 2-dicarboethoxyethylene)-2, 3-hidropyran was followed. Yield $34 \%$. Bp $104^{\circ} \mathrm{C}(0.35 \mathrm{~mm})$.

Mass spectrum: $\mathrm{M}^{+}=226$. (Calcd for $\mathrm{C}_{11} \mathrm{H}_{14} \mathrm{O}_{5}$ $=226$.)

Found: C, 58.19; H, 6.38.

Calcd for $\mathrm{F}_{11} \mathrm{H}_{14} \mathrm{O}_{5}$ : C, 58.40; H, 6.24.

\section{Polymerization Procedure}

The monomer was redistilled in ampoules in vacuo in a stream of dry nitrogen immediately before use. The monomer was identified to be pure by means of gas chromatography. A solution of monomer was placed in a hard glass reaction tube of $1.5 \mathrm{~cm}$ diameter and degassed at $10^{-1} \mathrm{mmHg}$ by means of several cycles of freezing and thawing. A solution of initiator was added dropwise to the frozen monomer solution under a nitrogen atmosphere and then the tube was sealed off. The reaction solution was allowed to stand for an appropriate time at a desired temperature. Then the reaction solution was poured into a large volume of a mixture of $\mathrm{MeOH}$-water $(1: 1)$. The polymer precipitated was collected by filtration, reprecipitated from acetone-water, drid in vacuo and weighed.

\section{Measurements}

The IR spectra were taken with a Hitachi EPI-G-2 infrared spectrophotometer. The NMR spectra were measured in carbon tetrachloride with TMS as an internal standard with a Japan Electron Optics Laboratory JNM-3H-60 spectrometer. The molecular weight of the polymer was determined with a Mechrolab vapor pressure osmometer, Model-302, at $25^{\circ} \mathrm{C}$ in acetonitrile or at $65^{\circ} \mathrm{C}$ in DMF.

Measurements of the dielectric constant and loss were carried out with G. R. Capacitance Bridge Type $1615 \mathrm{~A}$ at room temperature. Sample of $10 \mathrm{~mm}$ diameter, $1.45 \mathrm{~mm}$ thick disc were submitted for measurements.

\section{RESULTS}

\section{Syntheses of Monomers}

Four derivatives of 2, 3-dihydropyran, 2-(2,2dicyanoethylene)-2,3-dihydropyran(I), 2-(2-cyano2-carboethoxyethylene)-2, 3-dihydropyran(II) and 2-(2, 2-dicarboalkoxyethylene)-2, 3-dihydropyran (IIIa and IIIb), were synthesized by Knoevenagel reaction of acrolein dimer with malononitrile, ethyl cyanoacetate and alkyl malonate in the presence of sodium acetate in $95 \% \mathrm{EtOH}$.<smiles>N#CC(C#N)=CC1CCC=CO1</smiles>

I<smiles>CCOC(=O)/C(C#N)=C/C1CCC=CO1</smiles>

II<smiles>[R]OC(=O)C(=CC1CCC=CO1)C(=O)O[R]</smiles>

III
III, $\mathrm{R}=\mathrm{M}$

Table II. IR and NMR spectra ${ }^{a}$ of compounds I, II, and III

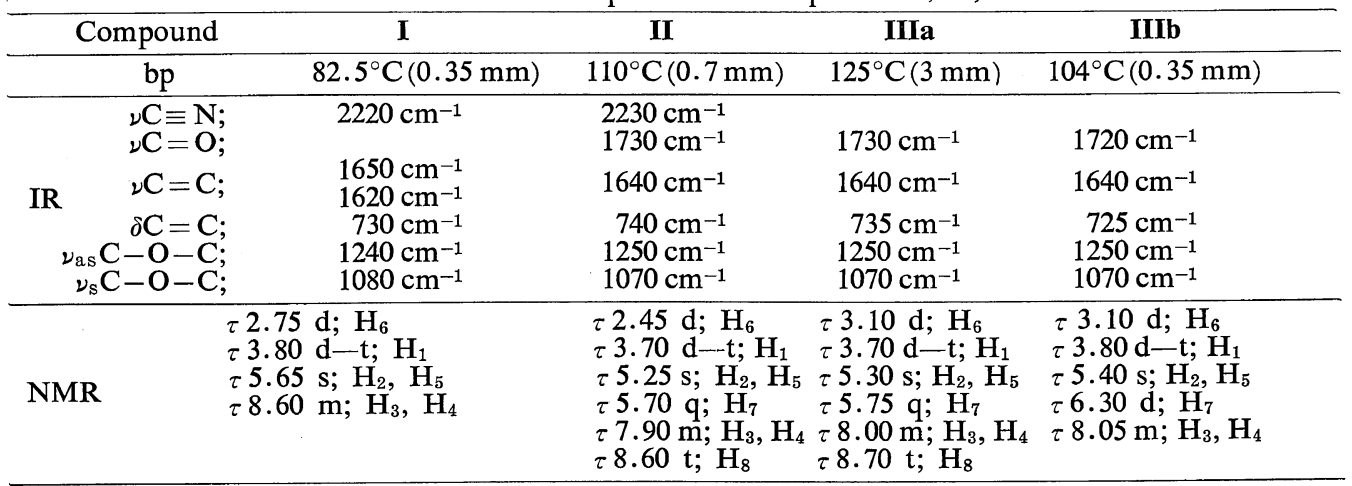

a d, doublet; t, triplet; q, quartet; s, sextuplet; $\mathrm{m}$, multiplet.

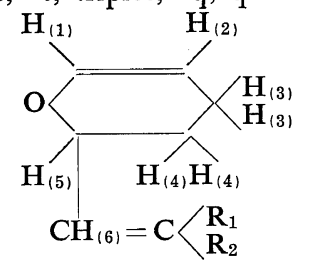

I , $\mathbf{R}_{1}=\mathbf{R}_{2}=\mathrm{CN}$

II , $\mathrm{R}_{1}=\mathrm{CN} \quad \mathrm{R}_{2}=\mathrm{COOCH}_{2} \mathrm{CH}_{3}$

IIIa, $\mathrm{R}_{1}=\mathrm{R}_{2}=\mathrm{COOCH}_{(7)} \mathrm{CH}_{(8)}$

IIIb, $\quad \mathrm{R}_{1}=\mathrm{R}_{3}=\mathrm{COOCH}_{(7)}$ 
These new compounds were identified respectively by elementary analyses, IR, NMR and Mass spectra. The data of the IR and NMR of these compounds are given in Table II.

Malononitrile readily reacted with acrolein dimer at room temperature to give $\mathbf{I}$ in a good yield. However, when the reaction was conducted at a higher temperature than $60^{\circ} \mathrm{C}$, the formation of large amounts of resinous products resulted. Also, when a relatively strong base such as piperidine was used as a catalyst, the reaction products were almost resinous ones. 2-(2, 2-Dicyanoethylene)-2, 3-dihydropyran (I) is a viscous liquid at room temperature with an unpleasant smell, crystallizing below $10^{\circ} \mathrm{C}$. By contrast, the condensation of ethyl cyanoacetate or alkyl malonate with acrolein dimer proceeded under reflux in EtOH and the formation of resinous products was not observed even in the presence of piperidine. These compounds are viscous liquids.

\section{Polymerization and Characterization of Polymers}

Polymerization of 2-(2,2-dicyanoethylene)-2, 3-dihydropyran. 2-(2, 2-Dicyanoethylene)-2, 3-dihydropyran was found to polymerize with cationic intiators such as $\mathrm{BF}_{3} \mathrm{OEt}_{2}, \mathrm{I}_{2}$ and $\mathrm{SnCl}_{4}$. The polymerization initiated by $\mathrm{BF}_{3} \mathrm{OEt}_{2}$ in dichloromethane proceeded homogeneously. Noticeably, a relatively high concentration of catalyst was required for the polymerization to occur at a low temperature $\left(-78^{\circ} \mathrm{C}\right)$ and when the catalyst concentration was below $10 \mathrm{~mol} \%$ to the monomer the polymerization occurred only very slightly. But, when carried out at $25^{\circ} \mathrm{C}$, the polymerization occurred to an appre- ciable extent even with the catalyst concentration of below $10 \mathrm{~mol} \%$ to the monomer. The polymer obtained was a white powder and decomposed gradually above $140^{\circ} \mathrm{C}$. It was easily soluble in acetone, soluble in acetonitrile, dimethylformamide (DMP) or pyridine, but insoluble in benzene, chloroform or alcohol. The molecular weight was about 2600.

In the case of the $\mathrm{I}_{2}$-catalyzed polymerization in diethyl ether, the polymer precipitated from the solution after $c a$. $60 \mathrm{hr}$. The conversion was very low.

The resulting polymer was a yellow mass and decomposed above $200^{\circ} \mathrm{C}$. In contrast to the polymer obtained by $\mathrm{BF}_{3} \mathrm{OEt}_{2}$ catalyst, it was insoluble in ordinary organic solvents. The results of the polymerization initiated by $\mathrm{BF}_{3} \mathrm{OEt}_{2}$ or $\mathrm{I}_{2}$ are summarized in Table III.

When the polymerization was initiated by $\mathrm{SnCl}_{4}$ in dichloromethane or in carbon tetracloride at $-78^{\circ} \mathrm{C}$ or at $25^{\circ} \mathrm{C}$, the polymerization rate was faster than that initiated by $\mathrm{BF}_{3} \mathrm{OEt}_{2}$ or $\mathrm{I}_{2}$, resulting in much higher conversions. In this case the polymer began to precipitate soon after the addition of $\mathrm{SnCl}_{4}$ to the monomer solution, and the polymer yield increased with the reaction time. The conversion at $25^{\circ} \mathrm{C}$ was higher than that at $-78^{\circ} \mathrm{C}$ and higher in dichloromethane than in carbon tetrachloride. The polymerization was not affected by oxygen but retarded by the addition of $\mathrm{H}_{2} \mathrm{O}$. As a result of the examination of the dependence of the monomer and initiator concentration on the polymerization in dichloromethane and in carbon tetrachloride, it was found that the polymerization rate increased with the increasing monomer

Table III. Polymerization of 2-(2, 2-dicyanoethylene)-2, 3-dinydropyran (I) with $\mathrm{BF}_{3} \mathrm{OEt}_{2}$ and $\mathrm{I}_{2}$

\begin{tabular}{|c|c|c|c|c|c|c|c|c|c|}
\hline No. & $\begin{array}{l}\text { Monomer } \\
\mathrm{mol} / l\end{array}$ & $\underset{\mathrm{m}}{\operatorname{Ini}}$ & $\begin{array}{l}\text { tiator, } \\
\mathrm{nol} / l\end{array}$ & $\begin{array}{l}\text { Solve } \\
\mathrm{m} l\end{array}$ & nt, & $\begin{array}{c}\text { Polymerization } \\
\text { time, } \mathrm{hr}\end{array}$ & $\begin{array}{c}\text { Polymerization } \\
\text { temp, }{ }^{\circ} \mathrm{C}\end{array}$ & $\underset{\%}{\text { Yield, }}$ & $M W$ \\
\hline 1 & 0.80 & $\mathrm{BF}_{3} \mathrm{OEt}_{2}$ & 0.40 & $\mathrm{CH}_{2} \mathrm{Cl}_{2}$ & 5 & 2 & -50 & 19.9 & 1800 \\
\hline 2 & 0.80 & "I & 0.40 & "I & 5 & 2 & -78 & 8.8 & 2600 \\
\hline 3 & 0.80 & " & 0.08 & " & 5 & 4 & -78 & 1.3 & - \\
\hline 4 & 0.80 & " & 0.08 & " & 5 & 24 & -78 & 2.4 & - \\
\hline 5 & 1.36 & " & 0.08 & " & 5 & 20 & +25 & 19.5 & - \\
\hline 6 & 1.36 & $\mathbf{I}_{2}$ & 0.027 & Ether & 5 & 27 & 0 & 1.1 & - \\
\hline 7 & 1.36 & " & 0.136 & $" \prime$ & 5 & 72 & 0 & 6.0 & - \\
\hline 8 & 1.36 & "I & 0.272 & " & 5 & 72 & 0 & 15.4 & - \\
\hline 9 & 1.36 & " & 0.272 & " & 5 & 24 & 0 & 1.4 & - \\
\hline
\end{tabular}


Synthesis of the Polymer with Polar Side Groups I.

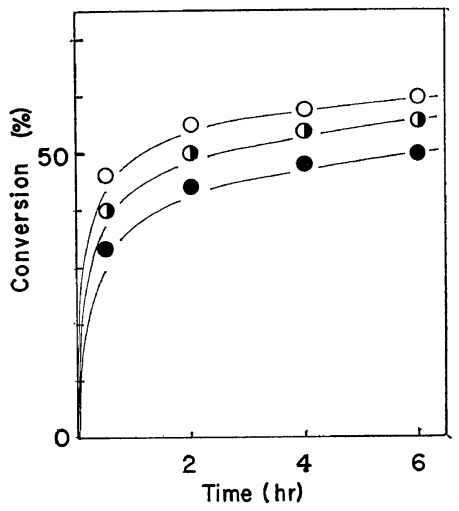

Figure 1. Effect of initiator concentration on polymerization of 2-(2, 2-dicyanoethylene)-2, 3-dihydropyran in carbon tetrachloride at $25^{\circ} \mathrm{C}$ : monomer concentration, $1.36 \mathrm{~mol} / l$; initiator $\left(\mathrm{SnCl}_{4}\right)$ concentration, $\bigcirc, 0.257 \mathrm{~mol} / l ; 0,0.171 \mathrm{~mol} / l$; $0.086 \mathrm{~mol} / l$.

and initiator concentration respectively, as shown in Figures 1 and 2. It should be noticed that when the initiator concentration was lower than $10 \mathrm{~mol} \%$ to the monomer the polymerization took place only slightly after a prolonged reaction time, although at $25^{\circ} \mathrm{C}$ the polymerization proceeded in a shorter period. The polymerization results are listed in Table IV. The polymer obtained was a slightly yellowish white powder and gradually decomposed above $180^{\circ} \mathrm{C}$. Its solubility was similar to the polymer obtained by $\mathrm{BF}_{3} \mathrm{OEt}_{2}$ catalyst. The molecular weight of the polymer were in the range of 1500 2600.

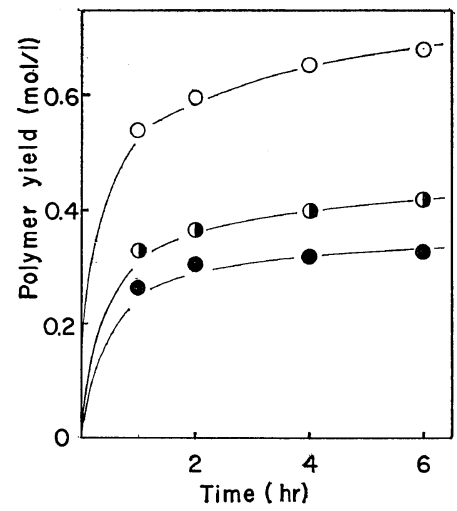

Figure 2. Effect of monomer concentration on polymerization of 2-(2, 2-dicyanoethylene)-2, 3-dihydropyran in carbon tetrachloride at $25^{\circ} \mathrm{C}$ : initiator $\left(\mathrm{SnCl}_{4}\right)$ concentration, $0.086 \mathrm{~mol} / l$; monomer concentration, $\bigcirc, 1.36 \mathrm{~mol} / l ; 0.75 \mathrm{~mol} / l$; - $0.68 \mathrm{~mol} / l$.

In these polymerizations, the formation of oligomer (solid) which are soluble in alcohol, also took place. Where the conversion was relatively low, most of the monomer was recovered from the reaction solution. For examples, in exptl no. 1 in Table IV, $16.6 \%$ of oligomers and $28.1 \%$ of monomer, and in exptl no. 4 in Table IV, $17.2 \%$ of oligomers and $69 \%$ of monomer were isolated from the reaction solution.

Polymerization of 2-(2-cyano-2-carboethoxyethylene)-2, 3-dihydropyran (II) and 2-(2, 2-dicarboalkoxyethylene)-2, 3-dihydropyran (III). The

Table IV. Polymerization of 2-(2, 2-dicyanoethylene)-2, 3-dihydropyran

(I) with $\mathrm{SnCl}_{4}$

\begin{tabular}{rcrrrrrrrr}
\hline No. & $\begin{array}{c}\text { Monomer, } \\
\mathrm{mol} / l\end{array}$ & $\begin{array}{r}\text { Initiator, } \\
\mathrm{mol} / l\end{array}$ & $\begin{array}{r}\text { Solvent, } \\
\mathrm{mol} / l\end{array}$ & $\begin{array}{c}\text { Polymerization } \\
\text { time, hr }\end{array}$ & $\begin{array}{c}\text { Polymerization } \\
\text { temp, }\end{array}{ }^{\circ} \mathrm{C}$ & $\begin{array}{c}\text { Yield, } \\
\%\end{array}$ & $M W$ \\
\hline 1 & 1.36 & 0.257 & $\mathrm{CH}_{2} \mathrm{Cl}_{2}$ & 5 & 6 & -78 & 51 & 1500 \\
2 & 1.36 & 0.171 & $\prime \prime$ & 5 & 24 & -78 & 43 & 2600 \\
3 & 1.36 & 0.085 & $\prime \prime$ & 5 & 24 & -78 & 0 & - \\
4 & 1.36 & 0.085 & $\prime \prime$ & 5 & 48 & -78 & 7 & - \\
5 & 1.53 & 0.257 & $\prime \prime$ & 5 & 2 & +25 & 91 & - \\
6 & 1.53 & 0.171 & $\prime \prime$ & 5 & 2 & +25 & 77 & - \\
7 & 1.53 & 0.086 & $\prime \prime$ & 5 & 2 & +25 & 43 & - \\
8 & 1.36 & 0.257 & $\mathrm{CCl}_{4}$ & 5 & 4 & +25 & 58 & - \\
9 & 1.36 & 0.171 & $\prime \prime$ & 5 & 4 & +25 & 55 & 2200 \\
10 & 1.36 & 0.086 & $\prime \prime$ & 5 & 4 & +25 & 48 & - \\
11 & 1.00 & 0.257 & $\mathrm{CH}_{2} \mathrm{Cl}_{2}$ & 5 & 2 & +25 & 11 & - \\
\end{tabular}


Table V. Polymerization of 2-(2-cyano-2-carboethoxyethylene)-2, 3-dihydropyran (II), 2-(2, 2-dicarboethoxyethylene)-2, 3-dihydropyran (IIIa) and 2-(2, 2-dicarbomethoxyethylene)-2, 3-dihydropyran (IIIb)

\begin{tabular}{|c|c|c|c|c|c|c|c|c|c|c|}
\hline No. & $\mathrm{Mo}$ & $\begin{array}{l}\text { nome } \\
\mathrm{mol} / / \mathrm{l}\end{array}$ & & $\begin{array}{l}\text { itiator, } \\
\mathrm{mol} / l\end{array}$ & Solv & $\begin{array}{l}\text { vent, } \\
\mathrm{m} l\end{array}$ & $\begin{array}{l}\text { Polymerization } \\
\text { time, } \mathrm{hr}\end{array}$ & $\begin{array}{c}\text { Polymerization } \\
\text { temp, }{ }^{\circ} \mathrm{C}\end{array}$ & $\begin{array}{c}\text { Yield, } \\
\%\end{array}$ & $M W$ \\
\hline 1 & II & 0.72 & $\mathrm{BF}_{3} \mathrm{OEt}_{2}$ & 0.36 & $\mathrm{CH}_{2} \mathrm{Cl}_{2}$ & 5 & 4 & -78 & 12.0 & 670 \\
\hline 2 & II & 1.06 & " & 0.25 & " & 5 & 20 & -78 & 13.0 & - \\
\hline 3 & II & 1.03 & " & 0.077 & " & 5 & 20 & +25 & 32.6 & - \\
\hline 4 & II & 1.03 & " & 0.077 & " & 5 & 20 & -78 & 10.9 & - \\
\hline 5 & II & 1.12 & $\mathrm{SnCl}_{4}$ & 0.08 & " & 5 & 20 & -78 & 32.3 & - \\
\hline 6 & II & 1.12 & " & 0.08 & " & 5 & 20 & +25 & 54.1 & - \\
\hline 7 & IIIa & 1.00 & $\mathrm{BF}_{3} \mathrm{OEt}_{2}$ & 0.25 & " & 5 & 20 & -78 & 29.8 & - \\
\hline 8 & IIIa & 1.00 & " & 0.25 & " & 5 & 20 & +25 & 56.9 & - \\
\hline 9 & IIIa & 0.98 & " & 0.08 & " & 5 & 20 & -78 & 11.3 & - \\
\hline 10 & IIIa & 0.72 & " & 0.36 & " & 5 & 2 & -78 & 12.4 & 650 \\
\hline 11 & IIIa & 1.00 & $\mathrm{SnCl}_{4}$ & 0.08 & " & 5 & 20 & -78 & 72.6 & - \\
\hline 12 & IIIa & 1.00 & " & 0.08 & " & 5 & 20 & +25 & 76.2 & - \\
\hline 13 & IIIb & 0.71 & $\mathrm{SnCl}_{4}$ & 0.04 & $\mathrm{CCl}_{4}$ & 5 & 20 & +25 & 50.0 & - \\
\hline 14 & IIIb & 0.71 & $" 1$ & 0.04 & $\mathrm{CH}_{2} \mathrm{Cl}_{2}$ & 25 & 20 & -78 & 81.8 & 1900 \\
\hline 15 & IIIJb & 0.71 & " & 0.04 & " & 5 & 20 & +25 & 88.5 & - \\
\hline
\end{tabular}

results of the polymerization of these monomers by $\mathrm{BF}_{3} \mathrm{OEt}_{2}$ or $\mathrm{SnCl}_{4}$ in dichloromethane are summarized in Table V. In sharp contrast to themonomer I, 2-(2-cyano-2-carboethoxyethylene)2, 3-hydropyran (II), and 2-(2, 2-dicarboethoxyethylene)-2, 3-dihydropyran (IIIa) and 2-(2, 2dicarbomethoxyethylene)-2, 3-dihydropyran (IIIb) could be polymerized to a conciderable extent at $-78^{\circ} \mathrm{C}$ by both $\mathrm{BF}_{3} \mathrm{OEt}_{2}$ and $\mathrm{SnCl}_{4}$ of below 10 mol\% concentration to the monomer. At $25^{\circ} \mathrm{C}$ the polymerization preceeded easily with both catalysts of below $10 \mathrm{~mol} \%$ concentration to the monomer. The molecular weight of the polymer was lower compared with the polymer derived from the monomer 1. All these polymers were obtained as white powders. Poly[2(2-cyano)-2,3-dihydropyran] formed by $\mathrm{SnCl}_{4}$ at $-78^{\circ} \mathrm{C}$ or at $25^{\circ} \mathrm{C}$ softened at $130^{\circ} \mathrm{C}$ or at $156^{\circ} \mathrm{C}$, respectively. The polymer formed by $\mathrm{BF}_{3} \mathrm{OEt}_{2}$ at $-78^{\circ} \mathrm{C}$ or at $25^{\circ} \mathrm{C}$ softened at $117^{\circ} \mathrm{C}$ or at $121^{\circ} \mathrm{C}$. They were soluble in benzene, chloroform, acetone or DMF, but insoluble in alcohol.

Poly[2-(2-cyano)-2,3-dihydropyran] obtained by $\mathrm{SnCl}_{4}$ at $-78^{\circ} \mathrm{C}$ or at $25^{\circ} \mathrm{C}$ softened at $250^{\circ} \mathrm{C}$ or at $141^{\circ} \mathrm{C}$, respectively. The polymer obtained with $\mathrm{BF}_{3} \mathrm{OEt}_{2}$ at $-78^{\circ} \mathrm{C}$ or at $25^{\circ} \mathrm{C}$ softened at $118^{\circ} \mathrm{C}$ or at $102^{\circ} \mathrm{C}$, respectively. They were soluble in benzene, acetone or DMF, but insoluble in chloroform or alcohol.
Poly[2-(2-cyano)-2,3-dihydropyran] obtained by $\mathrm{SnCl}_{4}$ at $-78^{\circ} \mathrm{C}$ or at $25^{\circ} \mathrm{C}$ softened at $210^{\circ} \mathrm{C}$ or at $176^{\circ} \mathrm{C}$, respectively. Its solubility was quite similar to that of poly-2-(2,2-dicarboethoxyethylene)-2,3-dihydropyran.

Structure of the Polymers. In the infrared spectra of all the polymers above prepared, the bands observed at 1650,1240 , and $730 \mathrm{~cm}^{-1}$ in the monomers, which are assignable to the $\mathrm{C}=\mathrm{C}$ group of the vinyl ether moiety, disappeared, but the band at $1080 \mathrm{~cm}^{-1}$ due to the stretching vibration of the $\mathrm{C}-\mathrm{O}-\mathrm{C}$ linkage and the band at $1620 \mathrm{~cm}^{-1}$ due to the $\mathrm{C}=\mathrm{C}$ stretching vibration of the dicyanoethylene moiety remained. It is thus indicated that the polymerization proceeded at the vinylic double bond of the vinyl ether moiety and that the polymer retained the tetrahydropyran ring, which is in accordance with the polymerization of dihydropyran and its derivatives reported by Potnis $^{3}$ and by Tamura, ${ }^{4}$ et al.

NMR spectra of these polymers were measured in hexadeutro acetone at an elevated temperature $\left(46^{\circ} \mathrm{C}\right)$. Although the spectra were not well resolved, broad signals were observed at the positions which are expected from the structure of the polymers. In poly[2-(2-cyano)2,3-dihydropyran], for example, the peaks appeared at arround 8.2, 5.3 and $2.4 \tau$. 
Synthesis of the Polymer with Polar Side Groups I.



Figure 3. Effect of initiator concentration on polymerization of 2-(2, 2-dicyanoethylene)-2, 3-dihydropyran in dichloromethane at $25^{\circ} \mathrm{C}$ : monomer concentration, $1.53 \mathrm{~mol} / l$; initiator $\left(\mathrm{SnCl}_{4}\right)$ concentration; $\bigcirc, 0.257 \mathrm{~mol} / l ; \quad$ O. $0.171 \mathrm{~mol} / l$; $0.086 \mathrm{~mol} / l$.

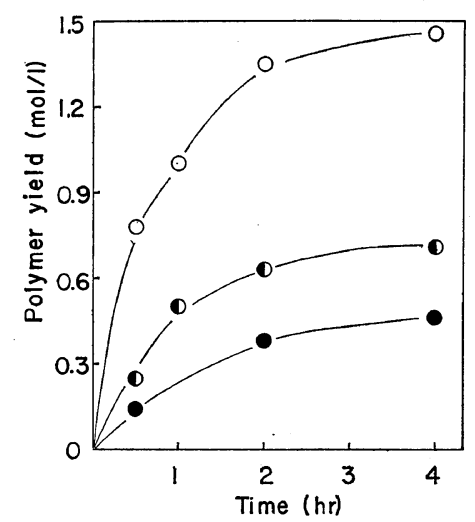

Figure 4. Effect of monomer concentration on polymerization of 2-(2, 2-dicyanoethylene)-2, 3-dihydropyran in dichloromethane at $25^{\circ} \mathrm{C}$ : initiator $\left(\mathrm{SnCl}_{4}\right)$ concentration, $0.257 \mathrm{~mol} / l$; monomer concentration: $\bigcirc, 1.53 \mathrm{~mol} / l ; \bigcirc, 0.75 \mathrm{~mol} / l ; \bullet, 0.51$ $\mathrm{mol} / l$.

Dielectric Properties of the Polymers. The dielectric constants measured at $1 \mathrm{kHz}$ were 5.25 for poly[2-(2-cyano)-2,3-dihydropyran], 4.38 for poly[2-(2,2-2-cyano)-2,3-dihydropyran] and 8.70 for poly[2-(2-cyano)-2,3-dihydropyran], respectively. Frequency versus dielectric constant $(\varepsilon)$ and dielectric loss $\left(\varepsilon^{\prime \prime}\right)$ curves are shown in Figures 5 and 6.

The dielectric constant of poly[2-(2-cyano)2,3-dihydropyran] was found to be relatively

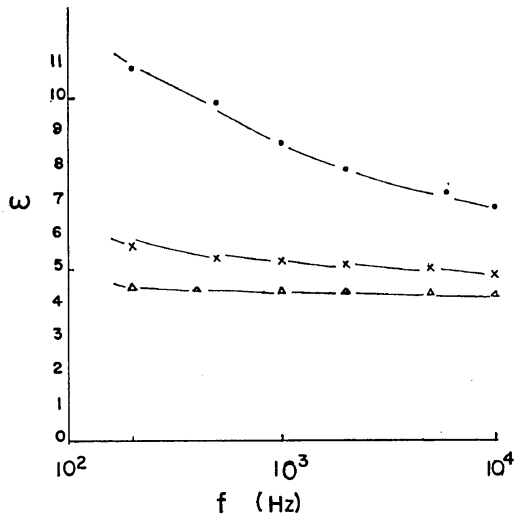

Figure 5. Dielectric constant $v s$. frequency curves: $\times, 2$-(2, 2-dicyanoethylene)-2, 3-dihydropyran; 2-(2-cyano-2-carboethoxyethylene)-2, 3-dihydropyran; $\triangle$, 2-(2, 2-dicarboethoxyethylene)-2, 3-dihydropyran.

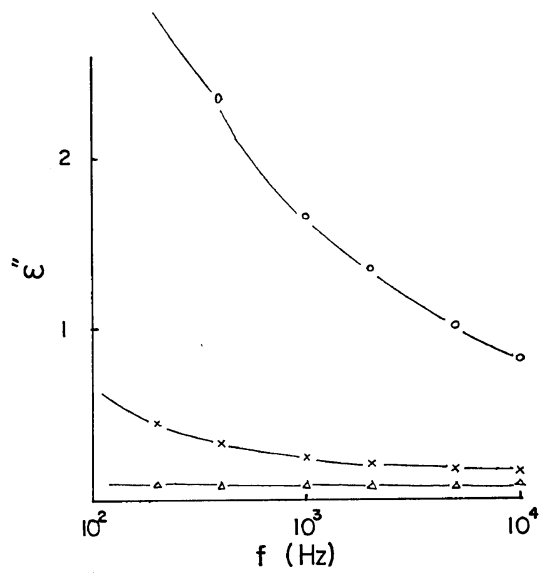

Figure 6. Dielectric loss vs. frequency curves: $\times$, 2-(2, 2-dicyanoethylene)-2, 3-dihydropyran; 2-(2-cyano-2-carboethoxyethylene)-2, 3-dihydropyran; $\triangle, 2$-(2, 2-dicarboethoxyethylene)-2, 3-dihydropyran.

lower than expected. The lower value seemes to be due to the difficulty of rotation of the side groups in the polymer. The higher value of poly[2-(2-cyano)-2,3-dihydropyran] than poly[2(2-cyano)-2,3-dihydropyran] may be due to the presence of ionic impurities in the polymer, which is implied from the frequency vs. dielectric loss curves.

\section{DISCUSSION}

Only few data are available in the literature 
concerning the polymerization of 2,3-dihydropyran and its derivatives. It has been reported that 2,3-dihydropyran and a few of its derivatives, e.g., 2-formyl-2, 3-dihydropyran, 2-acetyl6-methyl-2, 3-dihydropyran, 2-carbomethoxy-2methyl-2, 3-dihydropyran and 2-methyl-2-phenyl2, 3-dihydropyran, undergo cationic polymerization by $\mathrm{BF}_{3} \mathrm{OEt}_{2} \cdot{ }^{3,4}$

In the present study a new derivative of 2,3dihydropyran, 2-(2, 2-dicyanoethylene)-2, 3-dihydropyran (I), was synthesized and polymerized in view of the interest in the synthesis and the dielectric property of the polymer with flexible, polar side groups. In addition, the related monomers, 2-(2-cyano-2-carboethoxyethylene)-2, 3-dihydropyran (II) and 2-(2, 2-dicarboalkoxyethylene)-2, 3-dihydropyran (III) were synthesized, and polymerization features of these monomers were compared.

All these monomers polymerized by cationic initiators such as $\mathrm{BF}_{3} \mathrm{OEt}_{2}, \mathrm{SnCl}_{4}$ or $\mathrm{I}_{2}$, although they did not polymerize by benzoyl peroxide. Cationic nature of the polymerization was supported by the retarding effect of $\mathrm{H}_{2} \mathrm{O}$ and by the fact that the polymerization was not affected by $\mathrm{O}_{2}$. It was indicated from the IR spectra of the polymers formed that the polymerization proceeded at the double bond of the vinyl ether moiety, the tetrahydropyran ring being retained. The occurrence of the cationic polymerization indicates that these monomers function as the vinyl ether in spite of the presence of the electronegative dicyanoethylene, cyanocarboethoxyethylene or dicarboalkoxyethylene groups.

Generally, the rate of polymerization was faster in more polar solvent, dichloromethane than in carbon tetrachloride, and faster at $25^{\circ} \mathrm{C}$ than at $-78^{\circ} \mathrm{C}$. It increased with the increasing monomer and initiator concentration. $\mathrm{SnCl}_{4}$ was found to be a more effective catalyst than $\mathrm{BF}_{3} \mathrm{OEt}_{2}$. The average degree of polymerization was low.

The characteristic feature was found in the polymerization of the monomer I. While II, and especially IIIa and IIIb were easily polymerized by catalytic amounts of $\mathrm{BF}_{3} \mathrm{OEt}_{2}$ or $\mathrm{SnCl}_{4}$ even at $-78^{\circ} \mathrm{C}$, relatively high concentration of the initiator was required for the polymerization of I to occur at $-78^{\circ} \mathrm{C}$. In fact, when the initiator concentration was lower than $10 \mathrm{~mol} \%$ to the monomer, the polymerization occurred only very slightly, although at $25^{\circ} \mathrm{C}$ the polymerization took place easily with both initiators of below $10-\mathrm{mol} \%$ concentration to the monomer.

This may be explained mainly in terms of the complex formation of the nitrile group in the monomer $\mathbf{I}$ with the initiator. Although the carbon-carbon double bond, oxygen atom in the vinyl ether moiety or in particular, the ester group in the substituent can also be the complex-forming site in the monomers, the formation of a more stable co-ordination type complex between the nitrile group in the monomer I with the initiator may principally be responsible for the characteristic polymerization feature found in the present study. Although the monomer II also contains one nitrile group, the complex formation may be unfavorable in this case, possibly due to steric problem, since the nitrile group and the pyran ring may lie in the cis-position to each other.

The evidence of the complex formation was confirmed from the IR spectrum of the polymer derived from the monomer $\mathbb{I}$ with both $\mathrm{BF}_{3}$ $\mathrm{OEt}_{2}$ and $\mathrm{SnCl}_{4}$. It was observed that the absorption band due to the nitrile group splits into two absorptions at 2220 and $2290 \mathrm{~cm}^{-1}$ in the crude polymer obtained by pouring the reaction solution into $\mathrm{MeOH}$, while when the polymer was purified by repeated reprecipitations from acetone-water, the band at the higher frequency disappeared. The pure polymer shows only a single absorption band at 2220 $\mathrm{cm}^{-1}$. The band at the higher frequency observed in the crude polymer is assigned to the complexed nitrile group in the light of the report that the nitrile band generally shifts to a higher frequency by the complex formation..$^{5,6}$ Although the complex between the monomer and the initiator was not isolated in the present study, the finding that the polymer formed is complexed with the initiator strongly suggests the complex formation in the monomer state. In the crude polymer formed from II no splitting of the nitrile band was observed.

Since the complex appears to be more stable at lower temperature, the equilibrium may be more shifted toward the complex formation at 
Synthesis of the Polymer with Polar Side Groups I.

$-78^{\circ} \mathrm{C}$ than at $25^{\circ} \mathrm{C}$. The characteristic feature that the relatively high concentration of the initiator is required for the monomer I to undergo the polymerization at $-78^{\circ} \mathrm{C}$ may well be explained by the resonable assumption that only the uncomplexed, therefore, free initiator is effective for the initiation of the polymerization. Moreover, the complex appears to be rather unstable and dissociation may occur in polar solvents as has been observed in the complex between acrylonitrile and $\mathrm{ZnCl}_{2},{ }^{6}$ which, together with the acceleration of the propagation step in polar solvents, may be responsible for the faster polymerization rate in dichloromethane than in carbon tetrachloride.

The radical polymerization of vinyl monomers containing the ester or nitrile group has been reported to be accelerated by the complex formation with $\mathrm{ZnCl}_{2}{ }^{6}$ It may be interesting to study in detail how the monomer reactivity is influenced by the complex formation in the cationic polymerization by Friedel-Crafts type catalysts of vinyl monomers containing a strong donating site which is capable of forming a complex such as a nitrogen atom. Related to this, it has been found in our laboratory that the complex formation occurs also in the polymer- ization of vinyl acridine with $\mathrm{EtAlCl}_{2}$ or with $\mathrm{TiCl}_{4} \cdot{ }^{7}$

Acknowledgement. The authers wish to thank Mr. T. Shiba of Nippon Electric Company for measurements of dielectric properties.

\section{REFERENCES}

1. M. Okano and G. Tanabe, Japanese J. Appl. Phys., 38, 377 (1969).

2. H.W. Feilchenfeld, Trans. Faraday Soc., 62, 2084 (1966).

3. (a) V. Potnis and K. Shohara, Makromol. Chem., 63, 78 (1963); (b) J. N. Koral, ibid., 63, 217 (1963).

4. (a) A. Tamura and J. Murata, Kogyo Kagaku Zasshi (J. Chem. Soc. Japan, Ind. Chem. Sect.), 65, 642 (1962), (b) A. Tamura, et al., ibid., 67, (1964).

5. (a) M. Kubota and S. Schulze, Inorg. Chem., 3, 853 (1964); (b) H. J. Coerver and C. Curran, $J$. Amer. Chem. Soc., 80, 3522 (1958).

6. M. Imoto, T. Otsu, and M. Nakabayashi, Makromol. Chem., 65, 194 (1963).

7. Y. Seoka, K. Tanikawa, H. Hirata, S. Kusabayashi, and H. Mikawa, Chem. Commun., 1969, 652. 